\title{
Study on the Relationship between Expression of LGR5 and Clinicopathological Characteristics in Gastric Cancer Patients
}

\author{
Xiulian Xu1,2, Qijun Lv',2, Ping Xie ${ }^{1,2}$, Shoujiang Wei, ${ }^{1,2}$, Chongshu Wang1,2* \\ ${ }^{1}$ The First Department of General Surgery, Affiliated Hospital of North Sichuan Medical College, Nanchong, China \\ ${ }^{2}$ Courage Pancreatic Bowel Disease Institute, Affiliated Hospital of North Sichuan Medical College, Nanchong, China \\ Email: *chongs-wang@163.com
}

How to cite this paper: Xu, X.L., Lv, Q.J., Xie, P., Wei, S.J. and Wang, C.S. (2018) Study on the Relationship between Expression of LGR5 and Clinicopathological Characteristics in Gastric Cancer Patients. Health, 10, 159-169.

https://doi.org/10.4236/health.2018.101013

Received: January 3, 2018

Accepted: January 27, 2018

Published: January 30, 2018

Copyright (c) 2018 by authors and Scientific Research Publishing Inc. This work is licensed under the Creative Commons Attribution International License (CC BY 4.0).

http://creativecommons.org/licenses/by/4.0/

\section{(c) (i) Open Access}

\begin{abstract}
The aim of the study was to clarify the role of LGR5 in the process of formation and development of gastric cancer. The expression of LGR5 in gastric cancer and corresponding non-cancerous gastric tissues of 52 gastric cancer patients was assessed with the real-time fluorescence quantitative polymerase chain reaction (RT-PCR) and immunohistochemistry. We also analyzed the relationship between the expression level and clinicopathological characteristics. LGR5 gene and protein expression in gastric cancer tissues was in both cases significantly higher than in corresponding non-cancerous gastric tissues (both $\mathrm{P}<0.05$ ), but no significant relationship was found with clinicopathological parameters including tumor location, depth of invasion, differentiation, lymph node metastasis, stage, gender, age and carcinoembryonic antigen (CEA), and carbohydrate antigen 19-9 (CA19-9) level in peripheral blood preoperation of patients $(\mathrm{P}>0.05$, respectively). Furthermore, LGR5 gene expression was markedly higher in gastric cancer tissues of Helicobacter pylori (HP)-positive patients than negative ones $(\mathrm{P}<0.05)$. The result of the study showed that LGR5 might play a significant role in the process of formation and development of gastric cancer as an oncogene. Its effect might be strengthened by HP infection.
\end{abstract}

\section{Keywords}

LGR5, Clinicopathological Characteristics, Gastric Cancer, HP

\section{Introduction}

Stem cells are a kind of special cells with self-renewal ability, high proliferation 
and multi-directional differentiation potential, and play an important role in maintaining the integrity of tissue structure and function, repairing after injury and tumorigenesis. Tumor stem cells doctrine that tumor stem cells are primary cell lines in a class of self-renewal, infinite proliferation and multi-directional differentiation of cell subsets, is the tumor growth, metastasis, recurrence of the root causes. Leucine rich repeat containing G-protein-coupled receptor 5 (LGR5) is one of the known stem cell markers. It's widely distributed in the body, mainly expressed in the muscles, placenta, spinal cord, brain tissue, breast, hair follicles, eyes, genitals and gastrointestinal tract [1] [2]. Compared with the corresponding normal tissue, LGR5 is over expressed in human primary colon cancer, ovarian cancer, hepatocellular carcinoma [3] [4], suggesting that there is a certain correlation between LGR5 and tumor. LGR5 is the target gene of Wnt signaling pathway, which is involved in the formation of stem cell signaling network, and related to the occurrence and development of tumor [5]. The expressions of Wnt1, $\beta$-catenin and LGR5 in gastric cancer tissues were studied [6], It was found that Wnt1, $\beta$-catenin and LGR5 were expressed in the gastric mucosa, gastric precancerous lesions, and early gastric cancer. Gastric cancer showed a consistent trend, suggesting that Wnt signaling pathway in the development and progression of gastric cancer in the process of activation, and the occurrence and development of gastric cancer are closely related. The real-time quantitative reverse transcription polymerase chain reaction (RT-PCR) and immunohistochemistry were used to detect the expression of LGR5 in gastric cancer tissues in this study, and to explore the correlation between LGR5 and clinicopathological parameters, and to study the relationship between LGR5 and gastric cancer proliferation, to determine whether the LGR5 gene is a prognostic and recurrence of speculation indicators.

\section{Materials and Methods}

\subsection{Patient Characteristics}

After inform consent forms were signed, the specimens including gastric cancer and corresponding noncancerous gastric tissues in general surgery of affiliated hospital of North Sichuan Medical College during April to July in 2013 were collected. All cases were diagnosed as gastric adenocarcinoma with pathological biopsy both preoperation and postoperation. They who had taken anti-HP drug or chemotherapy or radiotherapy lately were removed. The clinicopathological characteristics of patients are summarized in Table 1.

\subsection{Samples}

All samples consisted of gastric cancer and corresponding non-cancerous gastric tissues were obtained intraoperation just after they were cut off. Then part was put into $-80^{\circ} \mathrm{C}$ refrigerator quickly used for total RNA extraction. The left was dipped in formalin and then embedded with paraffins for INH. 
Table 1. Patient clinicopathological characteristics.

\begin{tabular}{|c|c|}
\hline \multicolumn{2}{|c|}{ Characteristics $\mathrm{N}=52$} \\
\hline \multicolumn{2}{|l|}{ Gender Male 41} \\
\hline & Female 11 \\
\hline \multicolumn{2}{|c|}{ Age (years) Mean $58.6 \pm 11.7$} \\
\hline & Range $31-79$ \\
\hline \multicolumn{2}{|c|}{ Differentiation Well 2} \\
\hline & Moderate 14 \\
\hline & Poor 36 \\
\hline \multicolumn{2}{|c|}{ Location of tumor Upper 13} \\
\hline & Middle 14 \\
\hline & Lower 25 \\
\hline \multicolumn{2}{|c|}{ Depth of invasion [7] T1 10} \\
\hline & T2 10 \\
\hline & $\mathrm{T} 30$ \\
\hline & T4 32 \\
\hline \multicolumn{2}{|c|}{ Lymph node metastasis ${ }^{*}$ N0 20} \\
\hline & N1 10 \\
\hline & N2 14 \\
\hline & N3 8 \\
\hline \multicolumn{2}{|l|}{ Stage [8] I 15} \\
\hline & II 10 \\
\hline & III 24 \\
\hline & VI 3 \\
\hline
\end{tabular}

\subsection{Detection of HP}

14C-urea breath test simple, fast and inexpensive, sensitivity greater than 95\%, specificity greater than $90 \%$, HP infection for the first-line diagnosis [9]. Patients were arranged to take 14C-urea breath test to detect $\mathrm{HP}$ value preoperation. They whose HP values lower than $100 \mathrm{dpm}$ were regarded as negative, and the others positive. Due to cardia complete obstruction or poor compliance, $11 \mathrm{pa}-$ tients did not accept 14C-urea breath test.

\subsection{RT-PCR}

104 gastric cancer and corresponding non-cancerous gastric tissues were ground into fine powder with mortars and pestles in liquid nitrogen. Then total RNA was extracted with TRizol Reagent (Tiangen, China). Later the quality of total RNA was assessed with ultraviolet spectrophotometer (SHIMADZU, Japan) and agarose gel electrophoresis (agarose from Sigma, America; electrophoresis apparatus from BIO-RAD, America). cDNA was synthesized using reverse transcrip- 
tion kit (BioBRK, China) according to instruction. RT-PCR thermocycler (ABI, America) and kit (Takara, Japan) including Pre Mix, Dye and DNase/RNase free $\mathrm{ddH}_{2} \mathrm{O}$ were used for cDNA amplification. $1 \mu \mathrm{l}$ cDNA, $10 \mu \mathrm{l}$ Pre Mix, $2 \mu \mathrm{l}$ Dye, forward and reverse primer both $0.6 \mu \mathrm{l}(10 \mathrm{pmol} / \mu \mathrm{l})$ and $5.8 \mu \mathrm{l}$ DNase/RNase free $\mathrm{ddH}_{2} \mathrm{O}$ were consisted in amplification system. LGR5 and $\beta$-actin primers were synthesized by Invitrogen Company. The primer sequence, reaction condition and product size are all in Table 2. All samples were tested duplicately. After amplification finished, dissociation curve was analyzed to identify the uniqueness of product. $2^{-\triangle C T}$ was used as relative expression value.

\subsection{INH}

Paraffins embedded 104 gastric cancer and corresponding non-cancerous gastric tissues were sectioned to $3 \mu \mathrm{m}$ in thickness. After the slices were dipped in dimethylbenzene twice each for $10 \mathrm{~min}$, they were put into 100\% alcohol, 85\% alcohol and 75\% alcohol successively, and then washed with running water for deparaffinization. $3 \% \mathrm{H}_{2} \mathrm{O}_{2}$ covered the whole tissues on slices for $20 \mathrm{~min}$ at room temperature and away from light in order to block endogenous peroxidase activity. Heat antigen retrieval was performed in $0.01 \mathrm{M}$ citrate buffer (ph 6.0) at $95^{\circ} \mathrm{C}$ for $20 \mathrm{~min}$. Then slices were incubated with Rabbit anti LGR 5 monoclonal antibody (ABCAM, England) at a dilution of 1:150 (final concentration: 6.67 $\mu \mathrm{g} / \mathrm{ml})$ at $4^{\circ} \mathrm{C}$ overnight. At the next morning the slices were incubated with common secondary antibody (ABCAM, England) at room temperature for 15 $\mathrm{min}$. After colorated with diaminobenzidine and counterstained with hematoxylin, the reaction products were visible. All slices were assessed by two professors of pathology who had no knowledge of any clinic pathological characteristics of the patients. Immunohistochemical results were evaluated for intensity and staining frequency of nuclear and cytoplasmic components. The intensity of staining was graded 0 (negative), 1 (weak), 2 (moderate), and 3 (strong). The frequency was graded from 0 to 5 according to the percentage of positive cells as follows: 0 , there was no cell stained; $1, \leq 1 \% ; 2,2 \%$ to $\leq 10 \% ; 3,11 \%$ to $50 \% ; 4,51 \%$ to $80 \%$; $5, \geq 80 \%$. Two scores were $\geq 1$ points judged as positive for LGR 5 expression [10].

\subsection{Statistical Analysis}

T-test or One-way analysis of variance was used for PCR data statistics, and Chi-square test was used for INH results. $\mathrm{P}<0.05$ was considered to have statistical significance.

Table 2. Primer sequence, reaction condition and product size.

\begin{tabular}{clll}
\hline Primer name & \multicolumn{1}{c}{ Primer sequence } & Product size (bp) & \multicolumn{1}{c}{ Reaction condition } \\
\hline \multirow{2}{*}{ LGR5 } & CTCCCAGGTCTGGTGTGTTG & \multirow{2}{*}{149} & 1) $95^{\circ} \mathrm{C} 30 \mathrm{sec} 1 \mathrm{cycle}$ \\
& GAGGTCTAGGTAGGAGGTGAAG & & 2) $95^{\circ} \mathrm{C} 3 \mathrm{sec}$ \\
\multirow{2}{*}{$\beta$-actin } & $\begin{array}{l}\text { F GAGCTACGAGCTGCCTGAC } \\
\text { R GTAGTTTCGTGGATGCCAC }\end{array}$ & \multirow{2}{*}{120} & $60^{\circ} \mathrm{C} 30 \mathrm{sec} 40 \mathrm{cycles}$ \\
\hline
\end{tabular}




\section{Results}

\subsection{Expression of LGR5 Gene by RT-PCR}

\subsubsection{Expression of LGR5 Gene in Gastric Cancer and Corresponding Non-Cancerous Gastric Tissues}

The mean $\triangle \mathrm{CT}$ value of LGR5 in gastric cancer and corresponding non-cancerous gastric tissues were $7.67 \pm 1.80$; $9.11 \pm 2.37(t=-4.01, \mathrm{P}<0.05)$ Figure 1 .

\subsubsection{Relationship between LGR5 Gene Expression and HP of Gastric Cancer Patients}

The mean $\triangle \mathrm{CT}$ value of LGR5 in gastric cancer tissues of HP positive and negative patients were $6.71 \pm 1.63$ and $8.59 \pm 1.44$ respectively. The variation was significant $(\mathrm{P}<0.05$; Table 3$)$.

\subsubsection{Relationship between LGR5 Gene Expression and}

Clinicopathological Characteristics of Gastric Cancer Patient

The CEA data of 3 patients and CA19-9 of 2 patients were lost, so they were removed when made those two statistics analysis. No significant relationship was found between LGR5 and clinic pathological characteristics, including gender, age, tumor's location, depth of invasion, differentiation, lymph node metastasis, stage and CEA, CA19-9 level in peripheral blood reoperation, Table 4.

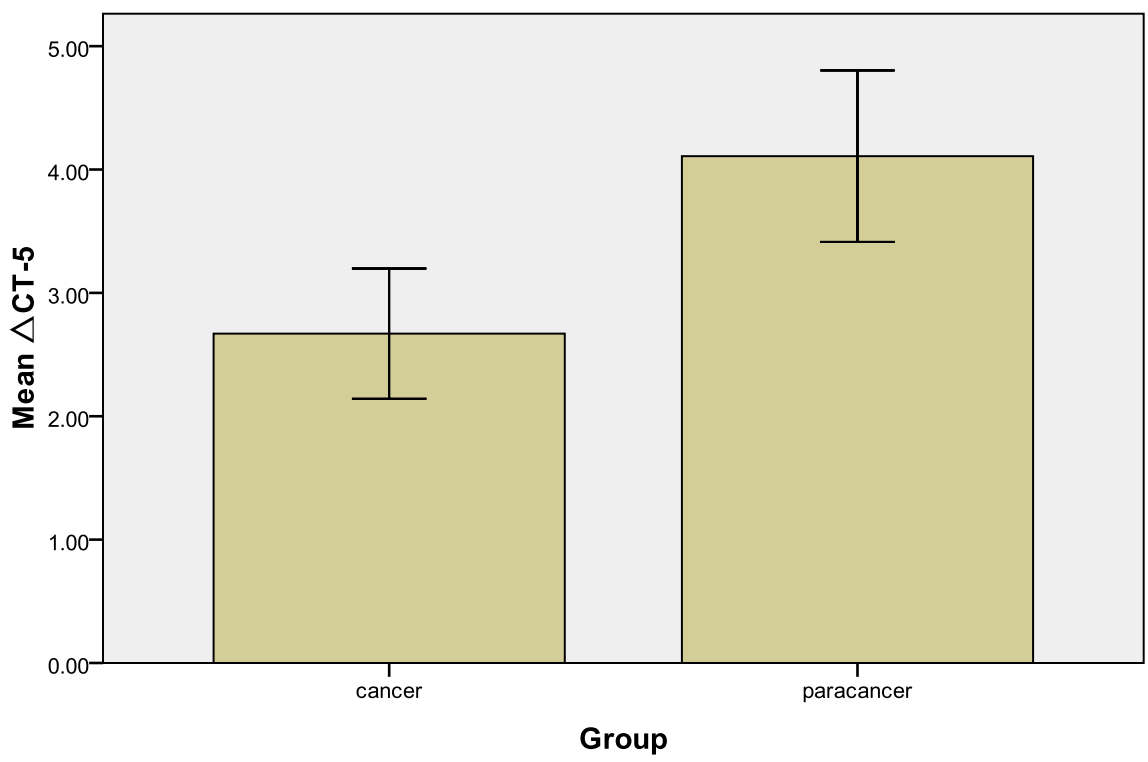

Figure 1. The mean $\triangle \mathrm{CT}$ value of LGR5 in gastric cancer and corresponding non-cancerous gastric tissues.

Table 3. The expression of LGR5 gene in gastric cancer tissues in HP.

\begin{tabular}{ccc}
\hline Group & N & LGR5 $\mathrm{p}$ \\
Mean $\Delta \mathrm{CT} \pm \mathrm{S}$ & & \\
\hline+ & 22 & $6.71 \pm 1.63<0.05$ \\
- & 19 & $8.59 \pm 1.44$ \\
\hline
\end{tabular}


Table 4. The expression of LGR5 gene in gastric cancer tissues in different clinicopathological characteristics.

\begin{tabular}{|c|c|c|c|}
\hline \multicolumn{4}{|c|}{ Characteristics Number of patients Expression of LGR5 gene Mean $\Delta \mathrm{CT} \pm \mathrm{SD} T / \mathrm{F} P$} \\
\hline \multicolumn{4}{|l|}{ Gender } \\
\hline Male & $419.26 \pm 2.30$ & 0.91 & 0.86 \\
\hline Female & $119.09 \pm 2.49$ & & \\
\hline \multicolumn{4}{|l|}{ Age (year) } \\
\hline-49 & $158.34 \pm 2.44$ & & \\
\hline $50-59$ & $129.38 \pm 2.38$ & -0.19 & 0.45 \\
\hline $60-69$ & $159.81 \pm 2.66$ & & \\
\hline $70-$ & $109.45 \pm 1.37$ & & \\
\hline \multicolumn{4}{|l|}{ Stage } \\
\hline I & $157.91 \pm 1.74$ & & \\
\hline II & $88.25 \pm 2.27$ & 1.05 & 0.38 \\
\hline III & $197.16 \pm 1.58$ & & \\
\hline IV & $78.38 \pm 1.83$ & & \\
\hline \multicolumn{4}{|l|}{ Lymph node metastasis } \\
\hline N0 20 & $7.68 \pm 1.95$ & & \\
\hline N1 10 & $7.92 \pm 1.83$ & 0.42 & 0.74 \\
\hline N2 14 & $7.38 \pm 1.67$ & & \\
\hline N3 8 & $8.38 \pm 2.05$ & & \\
\hline \multicolumn{4}{|l|}{ Differentiation } \\
\hline Moderate - well 16 & $7.76 \pm 1.82$ & -0.09 & 0.93 \\
\hline Poor 36 & $7.71 \pm 1.91$ & & \\
\hline \multicolumn{4}{|l|}{ Tumor, s location } \\
\hline Upper 13 & $7.87 \pm 1.52$ & & \\
\hline Middle 14 & $7.87 \pm 2.25$ & 0.14 & 0.87 \\
\hline Lower 25 & $7.57 \pm 1.79$ & & \\
\hline \multicolumn{4}{|l|}{ Depth of invasion } \\
\hline $\mathrm{T} 1-\mathrm{T} 220$ & $8.26 \pm 1.56$ & 0.63 & 0.63 \\
\hline T3 - T4 32 & $7.51 \pm 1.88$ & & \\
\hline \multicolumn{4}{|l|}{ CEA } \\
\hline (+) 6 & $8.89 \pm 2.79$ & -0.29 & 0.79 \\
\hline$(-) 43$ & $9.26 \pm 2.35$ & & \\
\hline \multicolumn{4}{|l|}{ CA19-9 } \\
\hline (+) 8 & $9.93 \pm 2.66$ & 0.71 & 0.50 \\
\hline$(-) 42$ & $9.11 \pm 2.34$ & & \\
\hline
\end{tabular}




\subsection{Expression of LGR5 Protein by INH}

The difference between positive rate of LGR5 protein in gastric cancer and corresponding non-cancerous gastric tissues, $86.5 \%(45 / 52)$ and $17.3 \%$ (9/52), was significant in statistics $(\mathrm{P}<0.01)$ (see Figure 2 and Figure 3 ).

\section{Discussion}

Leucine rich repeat containing G-protein-coupled receptor 5 is an independent $\mathrm{G}$ protein coupled receptor molecule, belonging to the $\mathrm{G}$ protein coupled hormone receptor family [1] [2], and contains a rich leucine repeat sequence in the gene; also known as G protein even Co-receptor 49 (GPR49). The human LGR5 gene is located on the chromosome 12q22-23 with a total length of $4208 \mathrm{bp}$, containing 22 exons and 21 introns. The transcripts produce 8 different mRNAs,

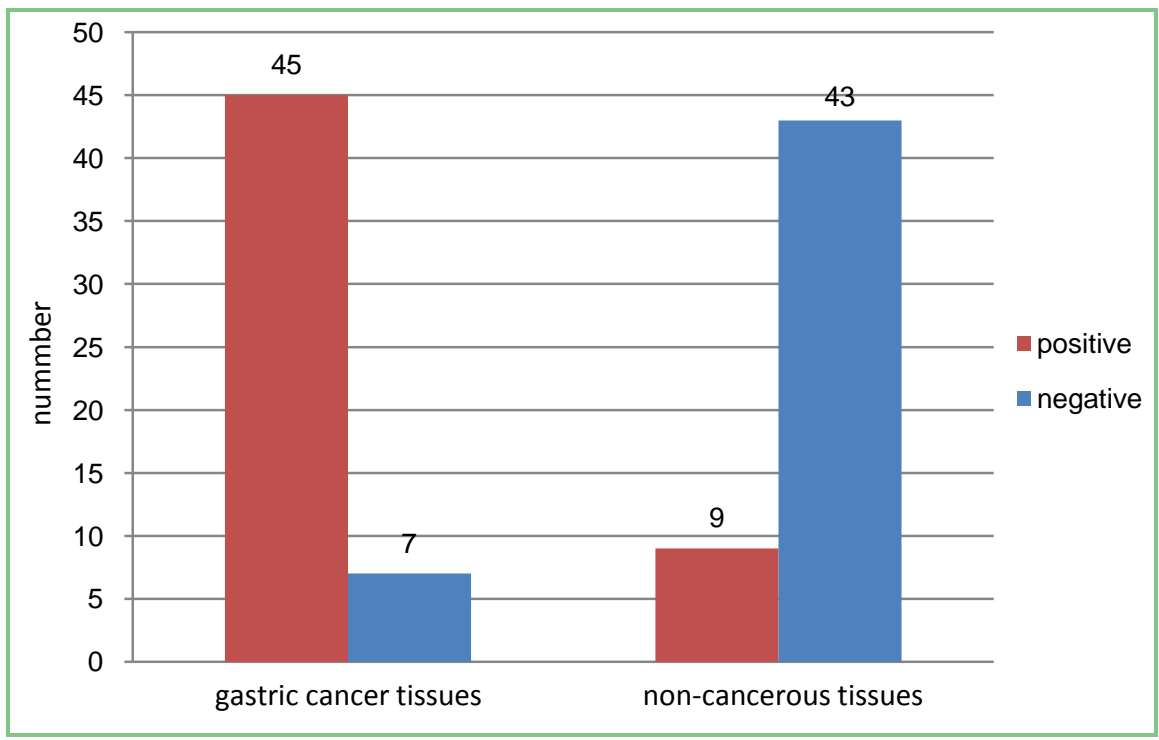

Figure 2. The expression of LGR5 protein in gastric cancer and corresponding non-cancerous gastric tissues.

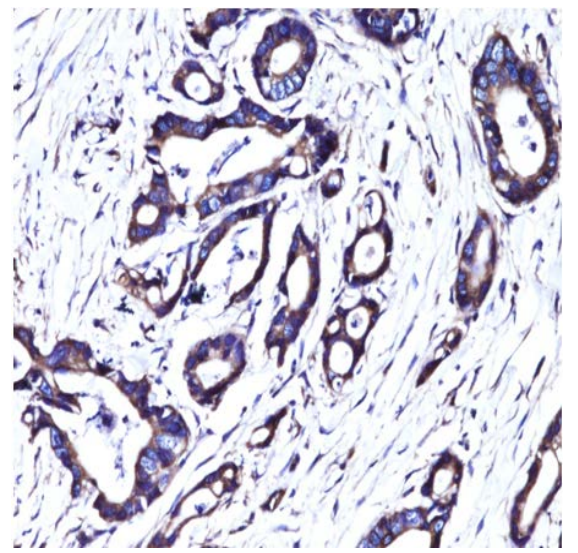

(a)

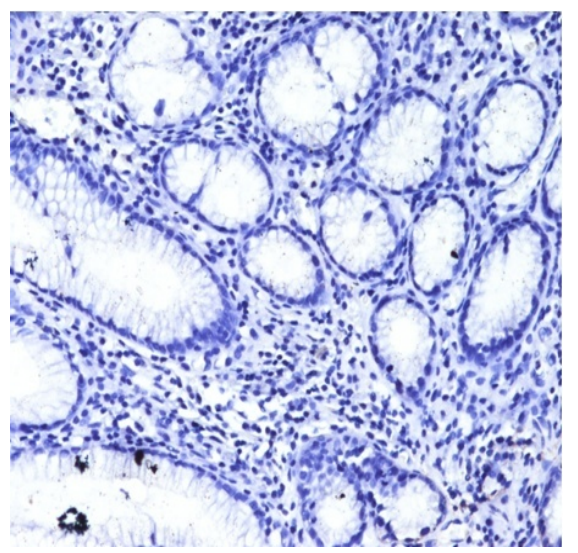

(b)

Figure 3. LGR5 protein expression in gastric cancer tissues (Positive) (a) and corresponding non-cancerous gastric tissues (Negative) (b) (both magnification $\times 200$ ). 
of which 5 are selective cutters, encoding a polypeptide chain consisting of 907 amino acid residues, including 21 signal peptides, 540 external functional regions, 263 transmembrane regions, $83 \mathrm{C}$-terminal tail. The coding product Lgr5 protein is characterized by 17 leucine-rich repeats in the externally functional region, $\mathrm{N}$-terminal and C-terminal flank-rich cysteine sequences with 4 glycosylation sites, 7 spiral transmembrane areas highly conserved [1] [2]. LGR5 is widely distributed in the human body, mainly expressed in muscle, placenta, spinal cord, brain tissue, breast, hair follicle, eye, genitals and gastrointestinal tract [1] [2]. G protein-coupled receptor LGR5 is the target gene for Wnt signaling pathway, which is involved in the formation of stem cell signaling network, and related to the occurrence and development of tumor [5]. Bjerknes et al. presented evidence of pluripotent stem cells in the gastric epithelium of adult mice using chemical induction markers, indicating the presence of multifunctional gastric stem cells [11]. In 2007, the first one able to confirm the origin and development of gastric cancer stem cells was found [12]. Barker et al. reported that all of the stomach glands originated from LGR5 positive cells, suggesting that LGR5 may be one of the molecular markers of gastric stem cells [13], and then this inference was confirmed [14]. LGR5 located in gastric cancer patients with gastric antrum, stomach small bend.

Studies have found that [6], from the adjacent gastric mucosa $\rightarrow$ gastric precancerous lesions $\rightarrow$ early gastric cancer $\rightarrow$ advanced gastric cancer, gastric mucosal tissue expression of LGR5 gradually increased, showing its expression changes throughout the process of gastric cancer. The occurrence of the development process plays an important role. If it can be found through the study and some of the pathological features of gastric cancer, then the preoperative endoscopic biopsy will help the initial assessment of the tumor to guide the clinical treatment. However, similar studies are few, the expression of LGR5 and gastric cancer pathology and HP value is related to the current domestic and foreign research which is inconclusive; its gastric cancer patients with peripheral blood CEA and CA19-9 levels and the relationship with the patient's gender, age, at home and abroad are not reported, which are worth further study and discussion. In this study, we used RT-PCR and immunohistochemistry to detect the expression of LGR5 in gastric carcinoma and adjacent normal tissues from the two levels of gene and protein respectively. The results were compared with the clinical data and tumor pathology. The results of this study show that, regardless of gene or protein levels, the expression of LGR5 in gastric cancer tissue was higher than the adjacent normal tissue, thus confirms it is a carcinogen [15] [16] [17]. And is independent of tumor lymph node metastasis, which is consistent with the findings of Yamanoi [18]. And have nothing to do with tumor differentiation, staging and other pathological features, which is inconsistent with $\mathrm{Bu}$ et al. [19], They found that the expression of LGR5 gene in intestinal type, moderate differentiation, stage I and stage II gastric cancer was more significant. The reason for its inconsistency may be related to the amount of specimens in this 
study, but whether there is any correlation between them in the future remains to be further studied. And also have nothing to do with tumor location, depth of invasion and other pathological features. There is a certain relationship between HP infection with the occurrence of gastric cancer [20] [21], which is the important starting factor to chronic atrophic gastritis, and can lead to gastric mucosal metaplasia, then gastric cancer of the liver [22] [23]. Uehara et al. suggested that LGR5 (+) epithelial stem cells were more susceptible to DNA damage than LGR5 (-) epithelial cells in patients with active HP-infected gastric cancer [24], suggesting that HP infection increased the risk of cancer by affecting human gastric epithelial stem cells and may be involved in the early stages of gastric cancer formation. This study have also been studied and analyzed, the results show that HP-positive gastric cancer in patients with LGR5 gene expression was significantly higher than HP-negative, which we speculate that HP infection and LGR5 factor interaction to promote the occurrence and development in gastric cancer. In addition, the present study also found that the expression of LGR5 gene in cancer tissues of patients with gastric cancer was not related to its sex and age, suggesting that there was no gender difference in the expression of LGR5 gene, nor increased with age. The CEA and CA19-9 can be used to assess the prognosis of patients with gastric cancer [25] [26], there has nothing to do between the expression of LGR5 gene in gastric cancer tissue with CEA and CA19-9 levels in preoperative peripheral blood, so we speculated that it cannot be Judgment of prognostic indicators. Study showed that LGR5 gene-positive patients with gastric cancer have a poor prognosis, but the difference was not statistically significant [19]. Therefore, the author next to the need to follow up the prognosis of patients with gastric cancer, and then analyze the relationship between LGR5 gene and prognosis of patients, to further study whether the LGR5 gene can be used to assess the prognosis of patients with gastric cancer. There is no relevant reports about mechanism of LGR5 gene in the occurrence and development of gastric cancer, so need us further study.

\section{References}

[1] Hsu, S.Y., et al. (1998) Characterization of Two LGR Genes Homologous to Gonadotropin and Thyrotropin Receptors with Extracellular Leucine-Rich Repeats and a G Protein-Coupled, Seven Transmembrane Region. Molecular Endocrinology, 12, 1830-1845. https://doi.org/10.1210/mend.12.12.0211

[2] Mcdonald, T., et al. (1998) Identification and Cloning of an Orphan G Protein-Coupled Receptor of the Glycoprotein Hormone Receptor Subfamily. Biochemical and Biophysical Research Communication, 247, 266-270. https://doi.org/10.1006/bbrc.1998.8774

[3] McClanahan, T., Koseoglu, S., Smith, K., et al. (2006) Identification of Over Expression of Orphan G Protein-Coupled Receptor GPR49 in Human Colon and Ovarian Primary Tumors. Cancer Biology \& Therapy, 5, 419-426. https://doi.org/10.4161/cbt.5.4.2521

[4] Yamamoto, Y., Sakamoto, M., Fujii, G., et al. (2003) Over Expression of Orphan G-Protein-Coupled Receptor, Gpr49, in Human Hepatocellular Carcinomas with 
Beta-Catenin Mutations. Hepatology, 37, 528-533.

https://doi.org/10.1053/jhep.2003.50029

[5] Katoh, M. (2007) Networking of WNT, FGF, Notch, BMP, and Hedgehog Signaling Pathways during Carcinogenesis. Stem Cell Reviews, 3, 30-38.

https://doi.org/10.1007/s12015-007-0006-6

[6] Wang, X.-Y. (2010) Expression of Wnt1, $\beta$-Catenin and Lgr5 in Gastric Lesions and Their Correlation. Dalian Medical University, Dalian.

[7] Wu, J.P., Qiu, F.Z., Wu, M.C., et al. (2008) Huang Jia Si Surgery. 7th Edition, People's Health Publishing House, Beijing, 1450.

[8] NCCN Clinical Practice Guidelines in Oncology Gastric Cancer (Including Cancer in the Proximal $5 \mathrm{~cm}$ of the Stomach). NCCN Guidelines.

[9] Che, X.B. and Liu, W.Z. (2002) Evaluation of Common Diagnostic Methods for Helicobacter pylori. Chinese Journal of Digestion, 22, 691-693.

[10] Simon, E., Petke, D. and Boger, C. (2012) The Spatial Distribution of LGR5+ Cells Correlates with Gastric Cancer Progression. PLOS ONE, 7, e35486:1-15. https://doi.org/10.1371/journal.pone.0035486

[11] Bjerknes, M. and Cheng, H. (2002) Multipotential Stem Cells in Adult Mouse Gastric Epithelium. American Journal of Physiology-Gastrointestinal and Liver Physiology, 283, G767-G777. https://doi.org/10.1152/ajpgi.00415.2001

[12] Qiao, X.T., Ziel, J.W., McKimpson, W., et al. (2007) Prospective Identification of a Multilineage Progenitor in Murine Stomach Epithelium. Gastroenterology, 133, 1989-1998. https://doi.org/10.1053/j.gastro.2007.09.031

[13] Barker, N., van-Es, J.H., Kuipers, J., et al. (2007) Identification of Stem Cells in Small Intestine and Colon by Marker Gene Lgr5. Nature, 449, 1003-1007.

https://doi.org/10.1038/nature06196

[14] Barker, N., Huch, M., Kujala, P., et al. (2010) Lgr5 Vesem Cells Drive Self Renewal in the Stomach and Build Long Lived Gastric Units in Vitro. Cell Stem Cell, 6, 25-36. https://doi.org/10.1038/nature06196

[15] Qiao, X.T. and Gumucio, D.L. (2011) Current Molecular Markers for Gastric Progenitor Cells and Gastric Cancer Stem Cells. Journal of Gastroenterology, 46, 855-865. https://doi.org/10.1007/s00535-011-0413-y

[16] Becker, L. (2008) Immunostaining of Lgr5, an Intestinal Stem Cell Marker, in Normal and Premalignant Human Gastrointestinal Tissue. Scientific World Journal, 8, 1168-1176. https://doi.org/10.1100/tsw.2008.148

[17] Simon, E., Petke, D., Böger, C., et al. (2012) The Spatial Distribution of LGR5 ${ }^{+}$Cells Correlates with Gastric Cancer Progression. PLoS ONE, 7, e35486. https://doi.org/10.1371/journal.pone.0035486

[18] Yamanoi, K., Fukuma, M., Uchida, H., et al. (2013) Over Expression of Leucine-Rich Repeat-Containing G Protein-Coupled Receptor 5 in Gastric Cancer. Pathology International, 63, 13-19. https://doi.org/10.1111/pin.12013

[19] Bu, Z., Zheng, Z., Zhang, L., et al. (2013) LGR5 Is a Promising Biomarker for Patients with Stage I and II Gastric Cancer. Chinese Journal of Cancer Research, 25, 79-89.

[20] Gisbert, J.P. (2011) Helicobacter pylori-Related Diseases: Dyspepsia, Ulcers and Gastric Cancer. Gastroenterology \& Hepatology, 34, 15-26. https://doi.org/10.1016/S0210-5705(11)70017-6

[21] Zhang, Q.Y. and Li, Q. (2006) Abdominal Surgery. People's Health Publishing House, Beijing, 157-161. 
[22] Weck, M.N., Gao, L. and Brenner, H. (2009) Helicobacter pylori Infection Anchronic Atrophic Gastritis: Associations According to Severity of Disease. Epidemiology, 20, 569-574. https://doi.org/10.1097/EDE.0b013e3181a3d5f4

[23] Ohata, H., Kitauchi, S., Yoshimura, N., et al. (2004) Progression of Chronic Atrophic Gastritis Associated with Helicobacter pylori Infection Increases Risk of Gastric Cancer. International Journal of Cancer, 109, 138-143. https://doi.org/10.1002/ijc.11680

[24] Uehara, T., Ma, D., Yao, Y., et al. (2013) H. pylori Infection Is Associated with DNA Damage of Lgr5-Positive Epithelial Stem Cells in the Stomach of Patients with Gastric Cancer. Digestive Diseases and Sciences, 58, 140-149. https://doi.org/10.1007/s10620-012-2360-8

[25] Zhang, Y.L., Xue, Y.W., Lan, X.W., et al. (2010) Research on the Prognostic Value of Tumor Markers CA19-9 and CEA in Gastric Cancer Metastasis and Prognosis. Journal of Harbin Medical University, 44, 181-184, 188.

[26] Ucar, E., Semerci, E., Ustun, H., et al. (2008) Prognostic Value of Preoperative CEA, CA19-9, CA72-4, and AFP Levels in Gastric Cancer. Advances in Therapy, 25, 1075-1084. https://doi.org/10.1007/s12325-008-0100-4 